\title{
NORMATIVIZACIÓN, OFICIALIZACIÓN Y NORMALIZACIÓN DE LA TOPONIMIA EN EUSKAL HERRIA
}

Bellver de Cerdanya, 3, 4 i 5 de juliol de 2003

Mikel Gorrotxategi

Intentaré ser breve. Antes que nada una precisión sobre terminología.

En anteriores trabajos ha sido común la utilización del término normalizar para referirse al trabajo de estandarización de los topónimos, pero creemos que normalizar es un término ambiguo y que además es más propio su uso en una fase final en la que el uso del topónimo se vuelve «normal». Por lo tanto para la labor de estandarización usaremos «normativizar» y entenderemos por «normalizar» el trabajo posterior a la oficialización de los nombres que busca que el uso de la forma estandarizada sea el común.

\section{Normativización}

Aunque la Academia es el órgano competente en materia de normativización y fruto de ese papel son las diferentes normativas a usar en dicho campo, no siempre se respeta y en algunos casos se oficializa en su contra, fundamentalmente por el intrusismo e incompetencia, unidos a una buena pero desastrosa buena voluntad.

Las principales fuentes de problemas a la hora de normativizar vienen dados por la situación del euskera y la distancia que hay entre las lenguas del país. En las zonas donde ha desaparecido el euskera los topónimos no sólo han sufrido transformaciones, a menudo arbitrarias sino que en muchos casos han sido sustituidos por otros más o menos «serios»: Atxuriaga>La Aceña, Etxaburu $>$ El Cárabo, Gorrondatxe $>$ La Salvaje, Larreagaburu $>$ Mina del Morro. En algunas zonas este proceso de sustitución fue especialmente relevante como consecuencia de las minas, que hicieron que algunos municipios viesen multiplicada su población por 10 en pocos años. Transformaciones curiosas serian: Muniziaga $>$ Murcielaga (por los murciélagos), Olabarrieta $>$ Barrietas, Larrineta $>$ La Reineta, Urdandegieta $>$ Urdan de Huerta, Lega- 
górriaga $>$ La Gorriga, ... En menor medida también se dan casos de traducciones Harbeltzaga $>$ Peñas Negras, Harana $>$ El Valle, ... aunque estás últimas son difíciles de descubrir.

En la zona vascófona el principal problema es digámoslo el carácter oral de los topónimos euskéricos. En el último siglo se ha dado un fenómeno por el que para muchos vasco hablantes, que son analfabetos en su lengua, entienden que la forma que aparece en los papeles, Bizkarguenaga, Monasteriobidea, Beaskoa, etc., son castellanas, mientras que las formas orales, Biskorna, Mostei, Bisku, etc., son las correctas en euskera. Si a este fenómeno le añadimos las transformaciones sufridas en los últimos años la situación es cuando menos delicada.

En el caso de los neo-topónimos la situación es igualmente delicada, ya que no es posible la adaptación de las palabras, sino su total traducción.

Las normas de normalización actuales las escribieron Patxi Salaberri y Mikel Gorrotxategi Nieto tomando como base las usadas para Navarra, corregidas y aumentadas con la experiencia de ese trabajo y de las labores que ha realizado la Comisión en los últimos años. El año que viene es probable que vea la luz una nueva edición de esas normas que incluya la experiencia del reciente trabajo de Bizkaia y las particularidades de la Vasconia peninsular, donde se ha empezado a normativizar la toponimia 1:25.000.

\section{Oficialización}

Una de los principales problemas que existen en los trabajos de regularización de la toponimia es la división de competencias, que es distinta en la Comunidad Foral de Navarra y en la Comunidad Autónoma del País Vasco.

En ambas la Real Academia de la Lengua Vasca / Euskaltzaindia es asesora, pero es uno de los pocos puntos en común.

\section{Navarra}

En la Comunidad Foral de Navarra los nombres de los topónimos menores así como los de las entidades son competencia del Gobierno y los ayuntamientos únicamente les compete los nombres de sus calles, lo que da lugar a curiosas paradojas cuando un término del monte se convierte en calle.

En Navarra ha habido dos grandes trabajos de normalización. El Nomenclátor Euskérico de Navarra (1990) que realizó en colaboración con la Academia en otra época que podríamos llamar más feliz, y la toponimia menor de Navarra que se publicó en el Boletín Oficial de Navarra. 
La toponimia mayor fue oficializada por el Parlamento navarro, tomando como base el trabajo de la Academia, aunque no se recogieron todas las propuestas y después se procedió a oficializar más formas en euskera a petición de algunos ayuntamientos, aunque las peticiones no siempre han prosperado.

La toponimia menor además de publicarse en el BON, con lo que se le dio rango oficial, se publicó en la colección Nafarroako Toponimia eta Mapagintza/Toponimia y Cartografía de Navarra. En dichos libros aparece la forma normalizada así como gran parte de la documentación recogida, incluso aquellos nombres que no se pudieron ubicar. Desafortunadamente, los mapas escala 1:10.000 incluidos en los libros son catastrales, al no tener curvas de nivel ubicar los topónimos en el mundo real es cuando menos dificultoso, al menos si no eres Harry Potter.

La toponimia menor en cuestión fue normativizada siguiendo la normativa de Euskaltzaindia por un grupo de trabajo en el que participaban tres miembros de la Comisión de Onomástica (Patxi Salaberri, Andres Iñigo y el recientemente fallecido Jimeno Jurio como director). La normativa en cuestión fue realizada por Patxi Salaberri y corregida y aprobada por la Comisión de Onomástica de Euskaltzaindia y publicada en el libro Nafarroa Toponimia eta Mapagintza / Navarra Toponimia y Cartografia (1991) en el que se hace un resumen de las labores de recogida, legislación, metodología, etc.

La normativa en cuestión recoge como norma básica que los topónimos se deben escribir en la lengua de su grafía original, (5.2. 1. Todo topónimo euskérico se escribirá con grafía vasca) cosa que se realizó. Esto que aparentemente es lógico entra en contradicción con la oficialización de los nombres de los pueblos y entidades menores que sólo se oficializaron en euskera en los de una de las tres zonas en las que está dividido el antiguo reino a nivel lingüístico, en la vascófona (norte) y en las otras dos zonas (mixta y castellana) solamente cuando «exista una denominación distinta, originaria y tradicional en vascuence, en cuyo caso se utilizarán antes». Es obvio que en la zona vascófona son oficiales los nombres castellanos cuando son distintos de los euskéricos como parece ser el caso de Altsasu y Alsasua (un ejemplo creíble sería Doneztebe/ Santesteban).

Esta normativa da lugar a dos absurdos. Por una parte, nombres idénticos son escritos de distinta forma Echauri/Etxauri por una decisión política que los adscribió a una zona u otra. Por otra parte los topónimos mayores (barrios y lugares incluidos), aparecen en únicamente castellano pero los topónimos menores del lugar aparecen en euskara, aunque en estos últimos hagan mención a los segundos, como es el caso de Orcoyen, que no ha podido oficializar su nombre en euskera, por lo que ha acudido a los tribunales, aunque en el término municipal sea oficial Orkoinxabal («Llano de Orkoien») así como Orkoienbidea («El Camino de Orkoien») en el vecino Arazuri. 
Como todo es susceptible de empeorar en los últimos años se ha dado un proceso de involución cuyo máximo exponente es Berriozar donde el ayuntamiento ha traducido los nombres de las calles que en realidad eran topónimos menores que habían pasado a ser calles por el desarrollo de la población. El encargado del área de Euskera y Medio Ambiente se justificó alegando que la culpable era la anterior corporación municipal «que impuso los dichosos topónimos».

\section{Comunidad Autónoma del País Vasco}

Al igual que en Navarra en esta Comunidad también la Academia es el órgano asesor tanto en el tan renombrado Estatuto de Autonomía como en el artículo 10 de la Ley Básica de Normalización. Hoy en día parece increíble que dicho artículo fuese aprobado por unanimidad.

El principal problema es el de la competencia. Los nombres de los ayuntamientos se decide por mayoría absoluta del pleno, al igual que en los concejos, que son los que dictaminan su nombre. En este caso se da la paradoja que el concejo decide su nombre pero no el de los barrios o calles que lo integran, que son competencia municipal.

Los nombres de las calles y barrios son la única competencia municipal.

La toponimia no municipal, la toponimia menor, exceptuando carreteras, parques y algunos lugares que tienen una designación oficial conocida es un campo sin barreras en lo que atañe a la normalización. Hay ayuntamientos que han sacado mapas municipales, pero desgraciadamente en la mayoría de los casos con más intenciones que conocimiento.

En 1986 la antecesora de la Consejería de Política Lingüística encargó un estudio de toponimia menor para hacer una cartografía de la Comunidad en escala 1:25.000. El trabajo lo realizó Deiker, empezando por Bizkaia y aunque parezca increíble en él no participó la Academia, ni en el diseño, ni en su supervisión ni siquiera, en la redacción de las normas de estandarización. Posteriormente se realizó Gipuzkoa y Arába. El trabajo de Bizkaia se ha vuelto a realizar y finalizó el pasado lunes 30 dada la falta de calidad. Sería deseable que las otras dos provincias se volviesen a estudiar en mayor profundidad. Este trabajo ha sido usado recientemente para realizar una cartografía de toda la Comunidad que regaló un periódico, así como los mapas municipales que simplemente copian sin mayores criterios.

Uno de los problemas que presenta este trabajo es la relación entre geógrafos y filólogos. Desafortunadamente la elección de los topónimos se encomendo a los primeros con lo que en las zonas más delicadas (zonas de pérdida del euskera) los topónimos seleccionados en muchas ocasiones no son los 
más indicados. Por poner dos ejemplos frente a Ajaran y Urizar se prefirió $E l$ valle de la Siesta y Los Cascajos, por quedar en el mapa un par de centímetros mejor. En esta última revisión de Bizkaia las cosas han mejorado, y aunque la metodología del trabajo marcada por el Gobierno no ha sido la más adecuada (se empezó la casa por el tejado), la presencia de la Comisión desde el principio, un grupo de trabajo competente y receptivo (los geógrafos han aceptado gustosos las sugerencias de los filólogos) han logrado que la calidad sea mucho mejor, aunque, como todo es mejorable.

Una labor interesante y necesaria es la que han hecho y hacen algunos ayuntamientos que encargan trabajos de toponimia para la oficialización de la misma.

En el campo de los callejeros municipales es donde probablemente la normalización es donde mejor funciona. Por medio de un acuerdo con EUDEL la Academia asesora a los ayuntamientos de forma gratuita tanto normalizando los callejeros (en un un sentido amplio de la palabra de forma que en muchos casos se normalizan caseríos, estradas etc.), como sobre otro tipo de cuestiones (trabajos de toponimia, normas subsidiarias, etc.). Este trabajo empezó hace tres años con realización y posterior publicación del libro Entidades de Población de la Comunidad Autónoma Vasca.

\section{Normalización}

El punto más complicado de todo este proceso, y su objeto, es la normalización entendiéndola como el uso normal de las formas estandarizadas. El uso normal quiere, o querría decir que en los medios de comunicación, y en la vida diaria sean esas las formas de uso. En este campo la situación es más diversa. Hay nombres que han alcanzado un grado de normalización alto (Gernika, Leioa, Donostia, Gasteiz, Arrasate,...) su uso es general en todos los ámbitos de la vida, pero desafortunadamente el uso de otros no es tan extendido. Es triste comprobar que el grado de normalización tiene una cierta relación con la política, pero eso es otra historia. 